\title{
The prosodic interpretation of sonorants in Dutch ${ }^{*}$
}

\author{
Bert Botma and Erik Jan van der Torre
}

Amsterdam University/HIL / Universiteit Leiden/HIL

\section{Introduction}

It has often been observed that in a large number of languages the phonetic realization of sonorant consonants - approximants, rhotics, laterals, and nasals varies according to their position in the segmental string (see, for instance, Harris 1997 and references there). As an illustration, consider the following surface contrasts found in $/ \mathrm{w}, \mathrm{j}, \mathrm{r}, \mathrm{l} /$ in standard Dutch: ${ }^{1}$

(1) Allophonic variation in Dutch sonorants

\begin{tabular}{llllll} 
a. syllable-initial: & \multicolumn{3}{c}{ b. syllable-final: } \\
week ['vek] & 'week' & eeuw ['ew] & 'century' \\
jacht ['jaxt] & 'yacht' & baai ['baj] & 'bay' \\
raap ['Rap] & 'turnip' & paar ['paj] & 'pair'2 \\
laat ['lat] & 'late' & taal ['tat], ['taw] & 'language'
\end{tabular}

Leaving aside the precise characterization of the phonetic contrasts involved, what unites the realizations of $/ \mathrm{w}, \mathrm{j}, \mathrm{r}, \mathrm{l} / \mathrm{in}$ (1a) is that they all involve a closer stricture of articulation. ${ }^{3}$ This (near-) contact is absent in the realization of the syllable-final sonorants in (1b). Indeed, the tendency to vocalize sonorants in this position is further illustrated by the fact that, for some speakers at least, there is a complete neutralization of final /el/ /ew/ and /il/ /iw/ (see also Van Reenen 1986). For such speakers forms of the kind in (2) are surface homonyms:

(2) Complete neutralization (for some speakers)

$\begin{array}{lllll}\text { geel } & \text { 'yellow' } & \text { geeuw } & \text { 'yawn' } & \text { ['yew] } \\ \text { meel } & \text { 'flour' } & \text { meeuw } & \text { 'gull' } & \text { ['mew] } \\ \text { Niels } & \text { 'id.' (name) } & \text { nieuws } & \text { 'news' } & \text { ['niws] } \\ \text { verniel } & \text { 'destroy' } & \text { vernieuw } & \text { 'renew' } & \text { [faf'niw] }\end{array}$

Observe that this process crucially applies in syllable-final context. No neutralization 
of $/ 1 \sim \mathrm{W} /$ is expected to occur in words like vernielen 'destroy INF' [far'nilə] and vernieuwen 'renew INF' [fə_'niwa].

The contrast in the realization of sonorants in (1) is not displayed by obstruents. If anything, final obstruents in Dutch are realized with more consonantal properties, since it is in this position that they surface predictably as voiceless: in Dutch, forms like noot/not/ 'nut' and nood /nod/ 'distress' converge on a single surface form ['not]. Phenomena of this kind, whereby final obstruents display only a subset of the contrasts found in initial position, are common in Germanic. They include neutralization processes such as final devoicing (as in, for instance, Dutch and German) and allophonic variation such as glottaling and lack of aspiration (as in, for instance, English). While an account of these processes is beyond the scope of this paper, it is important to note that this kind of behavior of final obstruents is different from that of final sonorants. While sonorants are prone to undergo vocalization, the common denominator of the various restrictions targeting obstruents seems to be the loss of complexity. In fact, if voicing and aspiration are taken to be vocalic properties (as they are in, for instance, Van der Hulst 1995; and Humbert 1995), then the loss of these properties would mean that obstruents and sonorants in final position display opposite behavior.

Based on the above observations, we would like to argue that the realization of (non-nasal) sonorants and obstruents in Dutch can be derived directly from their position in the prosodic structure, and can be straightforwardly accounted for if we distinguish between "consonantal" and "vocalic" positions within the domain of the syllable. More specifically, the claim that we make is that segments dominated by the onset receive more consonantal properties than segments dominated by the nucleus. Given the observed dichotomy between sonorants and obstruents in what are superficially identical positions, we further claim that the two segment types receive a different prosodic interpretation. That is, we hypothesize that there are two ways in which input CVC sequences are syllabified, depending on the nature of the final consonant. If this consonant is an obstruent, it occupies the onset position of an empty-headed syllable (cf. Kaye et al. 1990; Harris 1994; and Harris and Gussmann 1998 for arguments supporting this view). ${ }^{4}$ If, on the other hand, the final position is occupied by a sonorant, we argue that it is more properly analyzed as being dominated by the preceding syllable - a structure that is more in line with traditional views on syllabic organization (see e.g. Kahn 1976). In the analysis presented here, the syllabification that is proposed for sonorants is essentially in line with the phonetic observations regarding English /l/ reported by Sproat and Fujimura (1993): ${ }^{5}$

Consonantal gestures are attracted to the syllable margins ... Vocalic gestures are attracted to the syllable nuclei ... In syllable-final $/ 1 / \mathrm{s}$, the (vocalic) dorsal gesture is attracted to the nucleus of the syllable ... In syllable-initial cases, the reverse prediction is made. (1993:306) 
The present proposal therefore aims to hardcode this phonetic contrast directly into the phonological organization that underlies it.

The structure of this paper is as follows. Section 2 addresses the allophonic variation of sonorants in more detail by focusing on the distribution of "clear" and "dark" /l/ in Dutch. We take this variation as the basis of our prosodic hypothesis, the background of which is outlined in Section 3. Section 4 presents an optimalitytheoretic analysis of the data under consideration, which, we argue, accounts for the observed differences between obstruents and sonorants in a straightforward way. Section 5 concludes.

\section{Surface variation of /l/}

Most varieties of Dutch have a difference between so-called "clear" and "dark" /1/. The former, a lateral approximant [1], is found in syllable-initial position. The latter, represented as [ 1$]$, is typically realized as pharyngealized, involving noticeable retraction of the tongue root towards the pharynx wall and, in prepausal and preconsonantal position, the lack of contact between the tongue and the alveolar ridge (cf. Collins and Mees 1996:170). As outlined, we take this (near-) absence of oral stricture to be a vocalic property.

As regards dialectal variation, the variety of Dutch that we are concerned with has a clear phonetic contrast between [l] and [1]. However, in other dialects this difference may be less perspicuous. The Rotterdam and Amsterdam dialects, for instance, typically pharyngealize /l/ in both contexts, with pharyngealization being most prominent in syllable-final position. The Nijmegen dialect on the other hand is reported by Collins and Mees (1996: 170) to have clear /1/ in all contexts. Nevertheless, it should be stressed that in these varieties the realization of final /1/ is only relatively clear or dark. In absolute terms, final /// will invariably have a more vocalic articulation than its initial counterpart, and, furthermore, it is only in this context that $/ \mathrm{l} /$ can be realized as vocalized $[\mathrm{w}]$. It is this general contrast, in $/ \mathrm{l} /$ as well as in other sonorants, which we believe motivates their distinct representation. This claim - a phonological categorization of the phonetic continuum - is supported by the prediction that we find languages with two relatively clear instances of $/ 1$, languages with two relatively dark instances of $/ 1 /$, and languages with a relatively clear /l/ syllable-initially and dark /1/ syllable-finally — but not vice versa.

Now, bearing in mind our hypothesis that sonorants dominated by the onset have more consonantal properties than sonorants dominated by the nucleus, consider next the forms in (3). Observe here that instances of clear /1/ typically correspond with syllable onsets while instances of dark /1/ typically correspond with syllable codas: 
(3) a. Instances of clear /l/

lat ['lat ] 'slat'

plat ['plat] 'flat'

atlas [?atlas] 'atlas' b. Instances of dark /l/

$\begin{array}{lll}\text { bal } & {[\text { 'bał }]} & \text { 'ball' } \\ \text { baal } & {[\text { 'bał }]} & \text { 'bale' } \\ \text { halt } & {[\text { 'hałt }]} & \text { 'halt' } \\ \text { hulde } & \text { ['hyłdə] } & \text { 'praise' }\end{array}$

Apart from the contexts in (3) we also find /l/ intervocalically, as in willen ['vila] 'want INF' and wielen ['vila] 'wheel PL'. Following recent proposals by Harris (1997, 1999) in which he rejects the notion of ambisyllabicity, we assume that /l/ here forms the onset of the second syllable. This prosodic organization is reflected in the phonetic realization of intervocalic /l/. It is realized as (relatively) clear in comparison to the forms in (3b), and, while $/ \mathrm{l} / \mathrm{in}$ the forms in (3b) can be realized as vocalized $[\mathrm{w}]$, i.e. with complete absence of contact between the active and passive articulators, this is not possible when $/ 1 /$ is intervocalic.

It should in this respect be noted that Collins and Mees (1996:197), among others, observe that intervocalic dark — but not vocalized - /1/ does appear after low back vowels, such as in bollen ['bołə] 'bulb PL' and balen ['bałə] 'bale PL'. Rather than the result of its syllabic affiliation, the realization of /l/ here appears to be caused by a co-articulation effect triggered by the preceding vowel, which suggests that pharyngealization of intervocalic / $/$ depends on a similar feature being present in the preceding vowel. ${ }^{6}$ Hence, there are two properties - absence of oral stricture and pharyngealization - that are responsible for the vocalic realization of $/ 1 /$. The difference between the two seems to be that pharyngealization is not necessarily prosodically determined whereas the lack of oral stricture is. In the remainder of this paper we shall be concerned mainly with prosodically determined vocalization of $/ 1 /$. Before addressing this issue, we first outline the general prosodic organization that underlies our analysis.

\section{Segmental and syllabic organization}

As regards segmental structure, we follow Smith et al. (1989) and assume that the main opposition within the Dutch vowel system is that between tense and lax vowels (see also Van Oostendorp 2000). Like Smith et al., we assume that tense vowels are structurally complex as compared to lax vowels in that the former have a dependent structure (cf. Harris 1994 for a similar proposal). ${ }^{7}$

(4) a. tense vowel

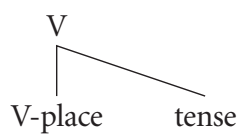

b. lax vowel

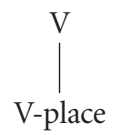


While we have little to say here about the precise featural composition of vowels, what is relevant for the present discussion is that we regard the V-nodes in (4) as constituting vocalic skeletal points which serve to identify the segments as vocalic for the purpose of prosodic interpretation. In addition, it is important to note that structures of the kind in (4a) are complex, i.e. branching, as compared to those of the kind in (4b). We will see below that this complexity has a direct bearing on the regularities holding at the level of syllable structure.

Although this paper does not specifically address segment-internal structure, we should note at this point that we assume that the manner component of segments consists of hierarchically organized constellations of $\mathrm{C}$ and $\mathrm{V}$ elements which enter into head-dependency relations (cf. Van der Hulst 1995). What is important for present purposes is that we take the most fundamental distinction to be that between $\mathrm{V}$-headed and C-headed segments, which correspond to the natural classes of sonorants and obstruents respectively.

The distinction between V-headed and C-headed segments plays an essential role in the syllabic interpretation of segments. Following the proposals in Van der Hulst (1995) and Golston and Van der Hulst (1999) we assume that syllable structure is a direct continuation of the segmental structure that it dominates. That is, syllables not only consist of the same type of elements as segments (Cs and Vs), but are also determined by the head properties of segments. However, it is important to realize that the syllable is not merely a projection of segmental structure but a phonological primitive in its own right. Syllables not only have a minimal size the nucleus - independent of segmental structure (that is, the nucleus may remain empty), but they also dictate the phonetic realization of segments. A case in point, we argue, is the allophonic variation of sonorants: these have a relatively consonantal interpretation when dominated by the onset (a C-position) and a relatively vocalic interpretation when dominated by the nucleus (a V-position).

As far as the general architecture of syllables is concerned, we follow Harris (1994) and adopt a model in which syllables are maximally binary branching. Given the representations in (4), the forms in (5) illustrate that this binarity is a requirement on monosyllabic outputs in that the nucleus of a stressed syllable must be branching at either the segmental or the syllabic level. Note that in the prosodic organization assumed here there is no equivalent of the positions traditionally referred to as "rhyme" and "coda". In our conception a closed syllable has the structure represented in (5b), where the "coda" consonant occupies the position that we refer to as "nuclear dependent". With this in mind, consider the structures in (5), where, for expository purposes, we represent onsets as ' $\mathrm{O}$ ', nuclei as ' $\mathrm{N}$ ', and syllables as ' $\sigma$ ', rather than as (projections of) Cs and Vs: 
(5) a

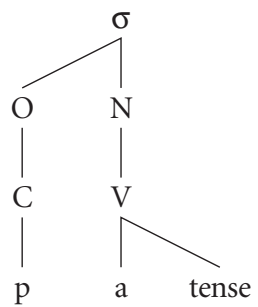

b.

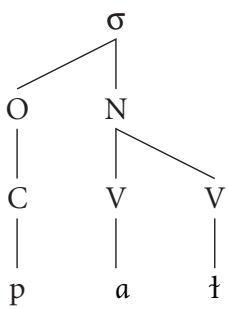

c.

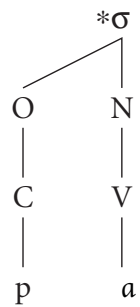

Following Prince (1990 et seq.) we refer to the requirement that syllables must be binary branching as the Stress-To-Weight Principle, forcing stressed nuclei to be heavy - or, in our terms, non-simplex:

(6) Stress-to-Weight Principle: Stressed nuclei must be branching. ${ }^{8}$

Next, as was mentioned above, we follow the main tenets of Government Phonology in that we regard word-final obstruents to be onsets of empty-headed syllables (cf. Kaye et al. 1990; Harris 1994; Harris and Gussmann 1998). ${ }^{9}$ However, we depart from this line of approach in that we argue that word-final sonorants are syllabified as part of the preceding syllable. That is, we propose the following distinct representations for the forms kat/kat/ 'cat' and bal/bal/ 'ball':

(7) a.

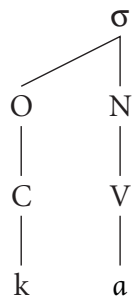

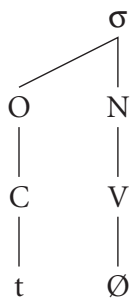

b.

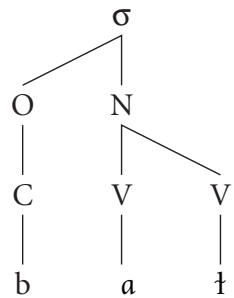

As a result, obstruent-final stems as in (7a) violate SWP. We will return to this issue below.

The organization of segments into syllables involves the interaction of segmental, or "bottom-up", and syllabic, or "top-down", requirements. These requirements are potentially conflicting, as the following example illustrates. From the point of view of bottom-up pressure, the optimal prosodic interpretation of a vocoid like /i/ would be to parse it as a nucleus. However, if /i/ happens to be followed by /a/, syllabic requirements may force /i/ to be parsed as an onset, in which case it surfaces as $[\mathrm{j}]$. The consonantal realization of $/ \mathrm{i} /$, then, follows directly from its syllabic position, and it is in this sense that the realization of segments is driven by top-down pressure. This top-down pressure is also the driving force behind the relatively consonantal and vocalic realizations of final sonorants. Thus, in a form like bal in (7b), the syllabification of /l/ under the nucleus yields [ 1 ] by virtue of it being linked to a $\mathrm{V}$-position.

In the OT analysis below we will be concerned mainly with the bottom-up 
pressure driving syllabification. Bearing in mind the different syllabic interpretation that we assign to final obstruents and sonorants, we take (8) and (9) to be the constraint-based interpretations of this pressure:

(8) Овs $\rightarrow$ Ons: Obstruents must be dominated by the onset.

(9) Son $\rightarrow$ Nuc: Sonorants must be dominated by the nucleus.

Since Oвs $\rightarrow$ Ons and Son $\rightarrow$ Nuc refer to distinct categories, there is no sense in which the two can be in conflict with each other. ${ }^{10}$ However, given the format of (8) and (9) we expect that constraints like Овs $\rightarrow$ Nuc and Son $\rightarrow$ ONs also play a meaningful role in the grammar - and these constraints do conflict with (8) and (9). First, as regards the interaction between Овs $\rightarrow$ Ons and Oвs $\rightarrow$ Nuc, there seems to be a universally fixed ranking Овs $\rightarrow$ ONs » Овs $\rightarrow$ Nuc, preventing obstruents from systematically appearing in the nucleus. Whether the relative ranking of Son $\rightarrow$ ONs and Son $\rightarrow$ Nuc is also fixed, is not so clear. There are, of course, many languages in which consonants cannot occur under the nucleus. However, it seems that — instead of a scenario where SoN $\rightarrow$ ONs outranks SoN $\rightarrow$ Nuc — this general restriction can be accounted for by a constraint along the lines of NoCoda ("Syllables may not have codas"; Prince and Smolensky 1993 et seq.). ${ }^{11}$ We leave constraint interaction of this kind for further research. For the purposes of this paper we will be concerned only with the constraints OBs $\rightarrow$ ONs and Son $\rightarrow$ Nuc.

\section{An OT account of the data}

Having provided the necessary theoretical background, we now turn to an OT interpretation of the data. We start the analysis by reiterating the idea that syllables minimally contain a nucleus, irrespective of whether this position is filled by segmental material. Below we take this to be an inviolable grammatical primitive, so that outputs violating it (e.g., ${ }^{*}[$ CV.C $]$ ) are excluded on principle (i.e., they are not part of the candidate set produced by Gen).

With this in mind, consider the tableaux in (10) and (11) where we evaluate two candidate outputs of the inputs /bal/and / bal/. In each case candidate (b), the monosyllabic parse, is optimal, since it crucially satisfies SWP and SoN $\rightarrow$ Nuc. In (10) and (11) these constraints are ranked above NoCoDA. This has been done for illustrative purposes only, since NoCoDa does not play a crucial role in the analysis developed below; we will omit it in the remainder of this article.

\begin{tabular}{|l||c|c|c|}
\hline \multicolumn{1}{|c||}{ (bal $/$} & SWP & Son $\rightarrow$ Nuc & NoCodA \\
\hline \hline a. [.'ba.lØ.] & $* !$ & $*$ & \\
\hline b. [.'bat.] & & & $*$ \\
\hline
\end{tabular}


(11)

\begin{tabular}{|l||c:c|c|}
\hline /bal/ & SWP & Son $\rightarrow$ Nuc & NoCoDA \\
\hline \hline a. [.'ba.l $\varnothing]$. & & $* !$ & \\
\hline b. [.'bat.] & & & $*$ \\
\hline
\end{tabular}

The optimal outputs in (10) and (11) have /l/ syllabified under the nucleus. As such, (10) and (11) reflect that, all things being equal, bottom-up pressure optimizes a prosodic organization in which sonorants are parsed under the nucleus. Observe, too, that we have argued above that the top-down pressure behind syllabification causes /l/ in this position to be realized with a vocalic articulation.

As far as intervocalic /1/ is concerned, recall that we follow Harris $(1997,1999)$ in that we abandon the device of ambisyllabicity (which, in optimality-theoretic terms, means that ambisyllabic outputs are not generated). Further, the ungrammaticality of an output like *[.vił.ə.] suggests that the familiar constraint ONSET ("Syllables have onsets"; Prince and Smolensky 1993 et seq.) is also operative, and must be ranked above SWP and SoN $\rightarrow$ Nuc. This results in the following constraint interaction for the inputs /vil+o/ and /vil+ə/:

(12)

\begin{tabular}{|l||c|c:c|}
\hline lvil+ə/ & ONSET & SWP & SON $\rightarrow$ NuC \\
\hline \hline a. [.'vi.lə.] & & $* !$ & $*$ \\
\hline c. [.'vit.ə.] & $* !$ & & \\
\hline
\end{tabular}

(13)

\begin{tabular}{|c||c|c:c|}
\hline$/$ ivil+a/ & ONSET & SWP & SON $\rightarrow$ Nuc \\
\hline \hline a. [.'vi.lə.] & & & $*$ \\
\hline c. [.'vił.ə.] & $* !$ & & \\
\hline
\end{tabular}

Although we shall not pursue this matter any further here, it is interesting to note that ONSET can essentially be interpreted as a generalized version of OBs $\rightarrow$ ONs (and, presumably, Son $\rightarrow$ ONs), favoring not just obstruents but any kind of consonant to occupy the onset position.

Turning our attention to final obstruents, recall that we argued that these are syllabified as onsets of empty-headed syllables. We have seen that this means that in obstruent-final stems SWP must be dominated by Oвs $\rightarrow$ ONs. This is illustrated in (14) for the input /kat/: 
(14)

\begin{tabular}{|l||c|c|}
\hline /kat/ & Oвs $\rightarrow$ ONs & SWP \\
\hline \hline a. [.'kat.] & $* !$ & \\
\hline b. [.'ka.tØ.] & & $*$ \\
\hline
\end{tabular}

The analysis presented so far might lead to the impression that Dutch bans obstruents from occurring under the nucleus altogether, but this is too strong a position because we find - admittedly infrequent - forms like dokter 'physician', optisch 'optic', and abdij 'abbey'. However, the existence of intervocalic obstruent-obstruent clusters is in no way problematic for our analysis if we make two additional, and uncontroversial, assumptions. First, the ill-formedness of outputs in which /kt/ forms part of the same onset can be attributed to the Sonority Sequencing Principle (Clements 1990). Second, like Harris (1994: 179ff.), we take the absence of vowel zero alternations in forms like dokter to reflect the lack of an empty position between the two obstruents. Note in this respect that there is a fundamental difference between word-final empty nuclei in outputs like [kat $\varnothing$ ] and word-internal empty nuclei in outputs like [dok Øtəx]. An exhaustive discussion of the difference between internal and final empty positions is beyond the scope of this paper; we refer the reader to Harris (1994) and Harris and Gussmann (1998) for details.

On these assumptions, consider now the tableau for the form dokter in (15) below, where Овs $\rightarrow$ Ons is dominated by two constraints. The correspondence constraint Dep-Nuc ("Do not insert a nuclear position") rules out candidate (b), which has an epenthetic empty position between the two obstruents. Observe that this constraint refers specifically to word-internal empty nuclei. In a more extensive account DEP-Nuc would presumably have to be broken down into two separate constraints, militating against the insertion of internal and final empty nuclei respectively. Next, the constraint SoN-SEQ ("Complex onsets rise in sonority, and complex codas fall in sonority"; cf. Kager 1999:267) rules out candidate (c), which has an ill-formed onset cluster:

(15)

\begin{tabular}{|c|c|c|c|c|}
\hline & /dəktər/ & Son-SeQ & DEP-NuC & OBs $\rightarrow$ ONs \\
\hline \multirow[t]{3}{*}{$\Leftrightarrow$} & a. [.'dək.təx.] & & & * \\
\hline & b. [.'do.kØ.tə..] & & $* !$ & \\
\hline & c. [.'do.ktə...] & $* !$ & & \\
\hline
\end{tabular}

The important point regarding (15) is that a heterosyllabic parse of the obstruent cluster violates Oвs $\rightarrow$ ONs, but is still more optimal than candidates (b) and (c). Hence, by virtue of the optimality-theoretic notion of constraint violability, obstruent clusters require no special treatment. Their interpretation is essentially no 
different from that of "regular" sonorant-obstruent clusters, as exemplified by the form hulde in (16):

(16)

\begin{tabular}{|l||c|c|c:c|}
\hline /hyldə/ & Oвs $\rightarrow$ ONs & ONSET & SWP & SON $\rightarrow$ NuC \\
\hline \hline a. [.'hył.də.] & & & & \\
\hline b. [.'hy.łdə] & & & $* !$ & $*$ \\
\hline c. [.'hyłd.ə.] & $* !$ & $\star$ & & \\
\hline
\end{tabular}

While our analysis offers a straightforward account of the syllabification of consonant clusters, it is clear that what is ultimately required is a finer-grained interpretation of the segmental and syllabic requirements driving prosodic organization. Consider in this respect our claim that the nucleus consists of V-positions. On such terms, it is perhaps not surprising that the only environment in which a final obstruent can be voiced is when it is syllabified as a nuclear dependent. An illustrative example is the form abdij, the representation of which is given in (17). Note here that since we are dealing with a monomorphemic form, there is no way of predicting where the voicing specification of the intervocalic cluster originates. ${ }^{12}$

(17)

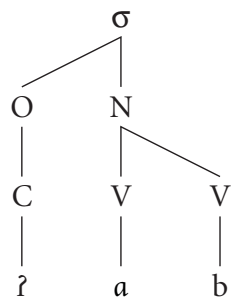

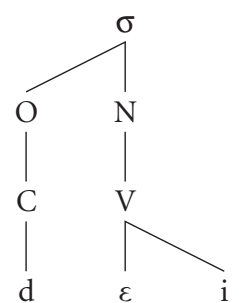

By the same token, the optimal output of a form like dokter will have a V-position dominating a voiceless obstruent. This suggests that in this case we are dealing with a more marked instance of syllabic affiliation, since the nucleus here dominates a segment which lacks any vocalic material whatsoever. Although we leave the precise nature of these mismatches for future research, we conjecture that they are the result of segmental requirements outranking syllabic requirements - or, in more general terms, of bottom-up pressure outweighing top-down pressure.

\section{Conclusion}

In this article we have provided a phonological interpretation of some familiar processes of allophonic variation involving sonorants in Dutch. Recapitulating, we have argued that this variation, essentially that of a relatively consonantal versus a 
relatively vocalic articulation, can be derived from the position of sonorants in prosodic structure. Given that we do not find this kind of variation in obstruents, we advanced the claim that there are two ways in which word-final consonants are syllabified. If the final consonant is an obstruent, it is syllabified as the onset of an empty-headed syllable. If, on the other hand, the final consonant is a sonorant, it is part of the preceding nucleus so that, accordingly, it receives its vocalic interpretation by virtue of being dominated by the nucleus. On these terms, we subsequently analyzed the surface variation encountered in an optimality-theoretic framework, using constraints that we believe are sufficiently general so as to deserve the status of universal conditions on sound structure.

\section{Notes}

* We are grateful to Colin Ewen, René Kager, Marc van Oostendorp, Piet van Reenen, Norval Smith, Richard Sproat and Jeroen van de Weijer for comments on an earlier version of this paper, and to audiences at the TIN-dag 2000 in Utrecht and at SCIL 12 at the University of Arizona in Tucson for helpful suggestions. Of course, none of the people mentioned above bear any responsibility for errors, omissions and shortcomings.

1. Observe that we are concerned here with allophonic variation of sonorants characterized by a non-complete oral closure, i.e. non-nasals. Apart from pharyngealization of final $/ \mathrm{n} /$ we find no significant allophony of nasals in Dutch (cf. Collins and Mees 1996). Note however that deletion of final nasals with concomitant regressive vowel nasalization is a cross-linguistically common process, and a prime example of the kind of allophony under consideration.

2. There are many realizations of $/ \mathrm{r} /$ in Dutch. Here we focus on a single contrast that is fairly frequent in standard western Dutch: a uvular trill $[\mathrm{R}]$ in initial position and a pre-velar approximant [r] in final position.

3. The consonantal articulation of initial / $\mathrm{j} /$ is arguably least perspicuous. Following Collins and Mees (1996:173) we represent the sound as a voiced palatal fricative [j].

4. Treating final obstruents as onsets of empty-headed syllables means that distributional restrictions on such obstruents (e.g. final devoicing, lack of aspiration) cannot be accounted for in terms of a condition on codas. In the analysis presented here a feasible approach would be to relate these restrictions to the reduced licensing capability of the following empty nucleus (cf. Harris 1994:210).

5. Allophonic variation of RP English /1/ is similar to that of Dutch /1/. English [ $\mathrm{t}]$ is velarized rather than pharyngealized, but this does not affect the point at issue.

6. Although an examination of the featural composition of segments is beyond the scope of the present paper, a suitable candidate would in this respect be the feature [A], referring to articulations which involve retraction (cf. Van der Hulst and Smith 1990).

7. According to Smith et al. the relevant feature is [I]. Here we refer to it simply as "tense".

8. Note that our conception of SWP is similar to that of foot binarity in Prince and Smolensky (1993), where feet must be binary under a syllabic or moraic analysis. 
9. Evidence in favor of this position includes the distributional symmetry between word-initial and word-final onsets and distributional generalizations regarding the size of the preceding nucleus. See Harris and Gussmann (1998) for persuasive arguments in favor of this line of thought.

10. We are grateful to René Kager for pointing this out to us.

11. In our account, NoCoda would have to be reformulated as a constraint which prohibits syllables to have a nuclear dependent.

12. This is not the case in obstruent-obstruent clusters that arise through compounding, which is another issue altogether.

\section{References}

Clements, G.N. (1990) 'The role of the sonority cycle in core syllabification.' In J. Kingston and M. Beckman, eds., Papers in Laboratory Phonology I: Between the Grammar and Physics of Speech. Cambridge University Press, Cambridge, 283-333.

Collins, B. and I. Mees (1996) The Phonetics of English and Dutch (Third revised edition). E. J. Brill, Leiden.

Golston, C. and H. van der Hulst (1999) 'Stricture is structure.' In B. Hermans and M. van Oostendorp, eds., The Derivational Residue. John Benjamins, Amsterdam, Philadelphia, $153-73$.

Harris, J. (1994) English Sound Structure. Blackwell, Oxford.

Harris, J. (1997) 'Licensing inheritance: an integrated theory of neutralization.' Phonology 14, $315-70$.

Harris, J. (1999) 'Release the captive coda: the foot as a domain of phonetic interpretation.' UCL Working Papers in Linguistics 11, 165-94.

Harris, J. and E. Gussmann (1998) 'Final codas: why the west was wrong.' In E. Cyran, ed., Structure and Interpretation - Studies in Phonology. Wydawnictwo, Lublin, 139-62.

Hulst, H. van der (1995) 'Radical CV Phonology: the categorial gesture.' In J. Durand and F. Katamba, eds., Frontiers of Phonology: Atoms, Structures, Derivations. Longman, London, $80-116$.

Hulst, H. van der and N. Smith (1990) 'Components for vowels and consonants.' Ms. Universities of Leiden and Amsterdam.

Humbert, H. (1995) Phonological Segments: Their Structure and Behavior. HIL Dissertation. The Hague, Holland Academic Graphics.

Kahn, D. (1976) Syllable-based Generalizations in the Phonology of English. Ph.D. Dissertation, MIT. Published 1980, Garland, New York.

Kager, R. (1999) Optimality Theory. Cambridge University Press, Cambridge.

Kaye, J., J-R. Vergnaud and J. Lowenstamm (1990) 'Constituent structure and government in phonology.' Phonology 7, 193-231.

Oostendorp, M. van (2000) Phonological Projection: A Theory of Feature Content and Prosodic Structure. Mouton de Gruyter, Berlin, New York.

Prince, A. (1990). 'Quantitative consequences of rhythmic organization.' In M. Ziolkowski, M. Noske and K. Deaton, eds., Parasession on the Syllable in Phonetics and Phonology. Chicago Linguistics Society, Chicago, 355-98.

Prince, A. and P. Smolensky (1993) 'Optimality theory: constraint interaction in generative grammar.' Ms. Rutgers University and University of Colorado, Boulder. 
Reenen, P.T. van (1986) 'The vocalization of /l/ in standard Dutch, a pilot study of an ongoing change.' In F. Beukema and A. Hulk, eds., Linguistics in the Netherlands 1986. Foris, Dordrecht, 189-98.

Smith, N., R. Bolognesi, F. van der Leeuw, J. Rutten and H. de Wit (1989) 'Apropos of the Dutch vowel system 21 years on.' In H. Bennis and A. van Kemenade, eds., Linguistics in the Netherlands 1989. Foris, Dordrecht, 133-42.

Sproat, R. and O. Fujimura (1993) 'Allophonic variation in English /1/ and its consequences for phonetic implementation.' Journal of Phonetics 21, 291-312. 